\title{
Relationship between performance, air ventilation efficiency and muscle oxygenation in Firefighters
}

\author{
Philippe Gendron, Eduardo Freiberger, Louis Laurencelle, François Trudeau, Claude Lajoie \\ From 15th International Conference on Environmental Ergonomics (ICEE XV) \\ Portsmouth, UK. 28 June - 3 July 2015
}

\section{Introduction}

Firefighting is a hazardous task associated with a heavy workload where task duration may be limited by air cylinder capacity. Increased fitness may lead to better air ventilation efficiency and task duration at a given heavy work intensity.

\section{Methods}

Thirteen male firefighters (age: $28.4 \pm 5.1$ years; height: $175.5 \pm 4.5 \mathrm{~cm}$; mass: $84.4 \pm 9.0 \mathrm{~kg} ; \mathrm{VO}_{2}$ peak: $47.8 \pm$ $5.1 \mathrm{mLO}_{2} \cdot \mathrm{min}^{-1} \cdot \mathrm{kg}^{-1}$ ) completed the following tests on 3 different days while wearing firefighting protective clothing (FPC), self-contained breathing apparatus (SCBA) and air cylinder: 1 - The graded walking test (GWT) for measuring different physiological parameters while connected to a metabolic system (gas exchanges); 2- The 10 METS treadmill test (T10) designed to measure the time to ventilate air from the cylinder at 10 METS, the intensity needed to complete the fire fit test work simulation described by Deakin et al. (1) within 8 min (2); 3The simulated work circuit (SWC) to measure the time needed to perform a test mimicking different firefighting tasks while wearing FPC and breathing with the SCBA. Participants performed the SWC as quickly as possible while respecting regulations of the test protocol. Moreover, skeletal muscle oxygenation (deoxyhemoglobin, $\mathrm{HHb}$ ) was measured during all three tests.

\section{Results}

Firefighters who performed the SWC in a shorter time had lower air cylinder ventilation values on the T10 $(r=$ -0.495, $P<0.05)$, better peak oxygen consumption $(r=$ -0.924, $P<0.001)$ during the GWT and performed

\footnotetext{
* Correspondence: claude.lajoie@uqtr.ca Canada

Laboratoire de physiologie de l'exercice, Département des sciences de l'activité physique, Université du Québec à Trois-Rivières, Trois-Rivières, original work is properly cited. The Creative Commons Public Domain Dedication waiver (http://creativecommons.org/publicdomain/ zero/1.0/) applies to the data made available in this article, unless otherwise stated. longer until exhaustion on the GWT $(r=-0.789, P<$ 0.001). Participants who completed the SWC more rapidly and reached a higher $\mathrm{VO}_{2}$ peak also had lower $\mathrm{V}_{\mathrm{E}}$ and $\mathrm{V}_{\mathrm{E}} / \mathrm{VO}_{2}$ values during submaximal workload on the GWT. Moreover, they had greater skeletal muscle deoxygenation during the SWC ( $\mathrm{HHb}, r=-0.593$, $P<0.05)$.

\section{Discussion}

Greater aerobic fitness was associated with greater air ventilation efficiency of faster firefighters on the SWC. According to Holmér and Gavhed (3), cardiovascular strain is lower in individuals with higher maximal aerobic capacity for a given submaximal intensity. Moreover, correlation between SWC completion time and $\mathrm{HHb}$ suggests that better aerobic fitness enhances deoxygenation in the vastus lateralis muscle during exercise where the aerobic process of energy production is solicited (4).

\section{Conclusion}

These results demonstrate that the fastest participants on the SWC had better air ventilation efficiency that could prolong interventions in difficult situations requiring air cylinder use. Moreover, the fastest participants had a greater skeletal muscle deoxygenation during the SWC.

\section{Published: 14 September 2015}

\section{References}

Deakin JM, Pelot RP, Smith JM, Stevenson JM, Wolfe LA, Lee SW, von Heimburg E, Rasmussen AK, Medbo J: Development of a bona fide physical maintenance standard for CF and DND fire fighters. Queen's University, Kingston, Ontario, Canada; 1996.

. Dreger RW, Petersen SR: Oxygen cost of the CF-DND fire fit test in males and females. Applied Physiology, Nutrition, and Metabolism 2007, 32(3):454-462. 
3. Holmér I, Gavhed D: Classification of metabolic and respiratory demands in fire fighting activity with extreme workloads. Applied Ergonomics 2007, 38(1):45-52.

4. Bae SY, Hamaoka TK, Katsumura T, Shiga T, Ohno H, Haga S: Comparison of muscle oxygen consumption measured by near infrared continuous wave spectroscopy during supramaximal and intermittent pedalling exercise. International Journal of Sports Medicine 2000, 21(3):168-174.

doi:10.1186/2046-7648-4-S1-A147

Cite this article as: Gendron et al:: Relationship between performance, air ventilation efficiency and muscle oxygenation in Firefighters. Extreme Physiology \& Medicine 2015 4(Suppl 1):A147.

Submit your next manuscript to BioMed Central and take full advantage of:

- Convenient online submission

- Thorough peer review

- No space constraints or color figure charges

- Immediate publication on acceptance

- Inclusion in PubMed, CAS, Scopus and Google Scholar

- Research which is freely available for redistribution

Submit your manuscript at www.biomedcentral.com/submit
() Biomed Central 